\title{
Thrombocytopenia in the critically ill: prevalence, incidence, risk factors, and clinical outcomes
}

\section{La thrombocytopénie chez les personnes gravement malades: prévalence, incidence, facteurs de risque et pronostics cliniques}

\author{
David R. Williamson, MSc • Olivier Lesur, MD, PhD • \\ Jean-Pierre Tétrault, MD • Vincent Nault, BSc • \\ Danielle Pilon, MD
}

Received: 29 February 2012/Accepted: 8 April 2013/Published online: 25 April 2013

(C) Canadian Anesthesiologists' Society 2013

\begin{abstract}
Purpose The aim of this cohort study was to describe the prevalence, incidence, and risk factors for thrombocytopenia in the intensive care unit (ICU) and to evaluate the impact of thrombocytopenia on mortality with further comparisons amongst major diagnostic categories.

Methods Patients admitted to the ICU from 1997-2011 for cardiac, medical, surgical, and trauma conditions were included. The presence of a platelet count $<100 \times 10^{9} \cdot \mathrm{L}^{-1}$ on admission day or its appearance during ICU stay were considered as prevalent and incident thrombocytopenia,
\end{abstract}

Electronic supplementary material The online version of this article (doi:10.1007/s12630-013-9933-7) contains supplementary material, which is available to authorized users.

Author contributions M. David Williamson designed the study and wrote the manuscript. M. David Williamson and M. Vincent Nault participated in the acquisition and analysis of data. M. David Williamson, Olivier Lesur, Jean-Pierre Tétrault, and Danielle Pilon participated in the interpretation of data. Olivier Lesur, Jean-Pierre Tétrault, Danielle Pilon, and M. Vincent Nault critically revised the manuscript.

This article is accompanied by an editorial. Please see Can J Anesth 2013; 60: this issue.

D. R. Williamson, MSc $\cdot$ O. Lesur, MD, PhD $\cdot$ J.-P. Tétrault, MD · V. Nault, BSc · D. Pilon, MD

Faculté de médecine et des sciences de la santé, Université de Sherbrooke, Sherbrooke, QC, Canada

D. R. Williamson, MSc ( $₫)$

Pharmacy Department, Hôpital du Sacré-Coeur de Montréal,

5400 Gouin West, Montréal, QC H4J 1C5, Canada

e-mail: david.williamson@umontreal.ca

D. R. Williamson, MSc

Faculté de pharmacie, Université de Montréal, Montréal, QC, Canada respectively. Risk factors for thrombocytopenia and the influence of thrombocytopenia on mortality were also analyzed.

Results This study included 20,696 patients. Prevalent and incident thrombocytopenia occurred in $13.3 \%$ and $7.8 \%$ of patients, respectively, with associated mortality rates of $14.3 \%$ and $24.7 \%$, respectively, compared with $10.2 \%$ in the group with normal platelet count $(P<0.001)$. After adjustments, thrombocytopenia remained associated with an increased risk of mortality (odds ratio 1.25; $95 \%$ confidence interval 1.20 to $1.31 ; P<0.001)$. The greatest impact of thrombocytopenia on mortality was observed in the cancer, respiratory, digestive, genitourinary, and infectious diagnostic categories. Independent risk factors included age, female sex, admission platelet counts and hemoglobin, mechanical ventilation, days of hospitalization prior to ICU admission, liver cirrhosis, hypersplenism, coronary bypass grafting, intra-aortic balloon pump placement, acute hepatitis, septic shock, and pulmonary embolism or deep vein thrombosis.

Conclusions Thrombocytopenia in the ICU is associated with an independent risk of mortality that varies greatly depending on diagnostic admission category.

O. Lesur, $\mathrm{MD}, \mathrm{PhD}$

Medical and Surgical Intensive Care Units, Centre Hospitalier Universitaire de Sherbrooke, Sherbrooke, QC, Canada

O. Lesur, MD, PhD - D. Pilon, MD

Department of Medicine, Centre Hospitalier Universitaire de Sherbrooke, Sherbrooke, QC, Canada

J.-P. Tétrault, MD

Department of Anesthesiology, Centre Hospitalier Universitaire de Sherbrooke, Sherbrooke, QC, Canada 


\section{Résumé}

Objectif L'objectif de cette étude de cohorte était de décrire la prévalence, l'incidence et les facteurs de risque de thrombocytopénie à l'unité des soins intensifs (USI) et d'évaluer son impact sur la mortalité en la comparant à d'autres catégories diagnostiques majeures.

Méthode Les patients admis à l'USI entre 1997 et 2011 pour un problème cardiaque, médical, chirurgical ou traumatique ont été inclus dans l'étude. La prévalence de thrombocytopénie était basée sur la présence d'une numération plaquettaire $<100 \times 10^{9} \cdot L^{-1}$ le jour de l'admission et son incidence obtenue à partir de la fréquence de son apparition pendant le séjour à l'USI. Les facteurs de risque de thrombocytopénie et l'influence de thrombocytopénie sur la mortalité ont également été analysés.

Résultats Cette étude a inclus 20696 patients. La prévalence et l'incidence de thrombocytopénie étaient de $13,3 \%$ et $7,8 \%$, respectivement, avec des taux de mortalité associée de $14,3 \%$ et $24,7 \%$, respectivement, par rapport à 10,2\% dans le groupe présentant une numération plaquettaire normale $(P<0,001)$. Après ajustements, la thrombocytopénie est restée associée à un risque accru de mortalité (rapport de cotes 1,25; intervalle de confiance $95 \%$ 1,20 à 1,31; P<0,001). L'impact le plus important de la thrombocytopénie sur la mortalité a été observé dans les catégories diagnostiques suivantes: oncologique, respiratoire, digestive, génito-urinaire et infectieuse. Les facteurs de risque indépendants comprenaient l'âge, le sexe féminin, les numérations plaquettaires et d'hémoglobineà l'admission, la ventilation mécanique, les jours d'hospitalisation avant l'admission à l'USI, la cirrhose du foie, l'hypersplénisme, le pontage aorto-coronarien, le placement d'un ballonnet intra-aortique, l'hépatite aiguë; le choc septique, et l'embolie pulmonaire ou la thrombose veineuse profonde.

Conclusion La thrombocytopénie à l'USI est associée à un risque indépendant de mortalité qui varie grandement selon la catégorie diagnostique à l'admission.

In the critically ill, thrombocytopenia is the most common coagulation abnormality. ${ }^{1}$ Depending on its definition (platelet count $<100 \times 10^{9} \cdot \mathrm{L}^{-1}$ or $<150 \times 10^{9} \cdot \mathrm{L}^{-1}$ ) and the category of patients in which it was studied, the prevalence and incidence of thrombocytopenia varied from 8.3$76.6 \%$ and from $13-44 \%$, respectively. ${ }^{2}$ Intensive care unit (ICU)-acquired thrombocytopenia has been associated with an increased risk of bleeding, blood product transfusion, progression towards multi-organ failure, and longer length of stay $^{3-6}$; however, ICU-thrombocytopenia has been inconsistently identified as an independent risk factor for mortality. ${ }^{5,7-10}$ Studies published to date have included selected patient populations, have been underpowered, and have evaluated and identified a limited number of risk factors. $^{2-4,9,11-15}$ In addition, these studies have failed to evaluate the relative importance of thrombocytopenia among different diagnostic categories. ${ }^{3,4,9,11-15}$ The relation between thrombocytopenia and bleeding has also been reported inconsistently. ${ }^{2}$

By using a very large and heterogeneous cohort of cardiac, medical, and surgical critically ill patients, this study aimed to evaluate the prevalence, incidence, and risk factors for thrombocytopenia and to evaluate its impact on bleeding, length of stay, and mortality in the critically ill, with further comparisons amongst major diagnostic categories.

\section{Methods}

The Research Ethics Committee of the Centre Hospitalier Universitaire de Sherbrooke (CHUS) approved the study $(12 / 2008)$ and waived the need for informed consent. This was a retrospective study conducted using data from the Centre informatisé de recherche évaluative en services et soins de santé (CIRESSS). The CHUS implemented a patient-oriented hospital information system (ARIANE; Per-Sé technologies, Georgia) in 1990. This single operational database includes all transactions of admission, diagnostics, therapeutics, and interventions. ${ }^{16}$ The CIRESSS research-purpose data warehouse of the CHUS is linked to the ARIANE system and updated every $24 \mathrm{hr}$. The database also incorporates MEDECHO data (Système de maintenance et d'exploitation des données pour l'étude de la clientèle hospitalière) required by the Quebec Ministry of Health. The data collected include demographics, detailed information on all primary and secondary diagnoses using International Classification of Diseases ninth revision (ICD-9) codes before 2006 and tenth revision ICD-10 codes after 2006, procedures using Canadian Classification of Diagnostic, Therapeutic, and Surgical Procedures before 2006 and the Canadian Classification of Health Interventions after 2006, and biochemical and clinical data. ${ }^{16}$ This database includes data on all admissions at the main site (Fleurimont) since 1997. Data from a second (Hotel-Dieu) site have been collected since 2001 . The CIRESSS was used in previously published studies. ${ }^{17-20}$ Although we did not formally validate data included in the database, diagnostic and procedures codes included in CIRESSS are those used for the MEDECHO database. The MEDECHO database was recently evaluated for the 14 comorbidities included in the Charlson comorbidity index and showed reliable coding. ${ }^{21}$ 
Study population

The study was conducted at the Centre Hospitalier Universitaire de Sherbrooke (CHUS), a tertiary care teaching hospital on two sites in Sherbrooke, Quebec, Canada. There are two ICU units at a first site, a mixed medical/ coronary unit and a surgical/trauma unit (16- and 14-bed capacity, respectively). There is also a general ICU with medical, coronary, and surgical patients at a second site (14-bed capacity). The patient population was composed of all patients aged $18 \mathrm{yr}$ and older admitted for more than 48 hr. The hospital database enabled the inclusion of patients admitted to the first site from 1997-2011 and the second site from 2001-2011. We further selected patients who had at least one platelet count measured within the first $24 \mathrm{hr}$ of admission. For patients with multiple ICU admissions during the study period, only the most recent admission was retained in order to capture mortality.

\section{Data collection}

We extracted all platelet counts and defined thrombocytopenia as at least one platelet count $<100 \times 10^{9} \cdot \mathrm{L}^{-1}$ during the ICU stay. We further defined moderate and severe thrombocytopenia as at least one platelet count of $50-100 \times 10^{9} \cdot \mathrm{L}^{-1}$ or $<50 \times 10^{9} \cdot \mathrm{L}^{-1}$, respectively. Thrombocytopenia was considered present on admission if it was already present or occurred during the first day of ICU admission, and it was then labelled "prevalent thrombocytopenia". Thrombocytopenia acquired in the ICU was defined as thrombocytopenia occurring in the days following ICU-admission and was considered "incident thrombocytopenia". We identified factors associated with thrombocytopenia to be evaluated after a literature review of published studies $3,9,11,13-15,22,23$ and overviews (Appendix 1). ${ }^{24,25}$

Admission diagnoses were classified into 14 categories based on ICD-9 and ICD-10 codes (Table E1; available as electronic supplementary material). The predicted outcome of patients at admission was assessed with the Charlson comorbidity index ${ }^{26}$ which was calculated using ICD-9 (1997-2006) and ICD-10 (2006-2011) codes at admission as previously described. ${ }^{27-29}$ The Charlson score has been shown to correlate with APACHE II scores and mortality in critically ill patients and is a reasonable alternative when acute illness scores are not systematically calculated. ${ }^{30,31}$

The presence of comorbidities and illnesses associated with thrombocytopenia were identified using ICD-9 and ICD-10 codes (Table E2; available as electronic supplementary material). Severe bleeding was defined as the presence of selected bleeding conditions during the index hospitalization (Table E3; available as electronic supplementary material). ${ }^{32}$ In the case of heparin-induced thrombocytopenia (HIT), it was defined as a positive PF4/ heparin ELISA test.

We also used the Canadian Classification of Diagnostic, Therapeutic, and Surgical Procedures before 2006 and the Canadian Classification of Health Interventions after 2006 to consider the following interventions associated with thrombocytopenia if they were performed or started prior to the onset of thrombocytopenia: hemodialysis, extracorporeal circulation, coronary bypass grafting, intra-aortic balloon pump placement, splenectomy, and blood transfusion (Table E2; available as electronic supplementary material). Blood transfusion was further defined as the patient having received at least one unit of packed red blood cells during the ICU stay. In patients without thrombocytopenia, interventions were considered if they occurred during the ICU stay.

Statistical analysis

We expressed continuous data as means (standard deviation) or as medians [25th and 75th percentiles] for continuous data according to distribution, and we expressed categorical data as percentages. Lengths of stay in the ICU were compared with the log-rank test. We used the Chi square test to compare major bleeding and mortality between patients with prevalent or incident thrombocytopenia and those without.

To select variables to be included in a multivariable model, we first used univariable logistic regression to analyze risk factors for thrombocytopenia in patients who developed incident thrombocytopenia while in the ICU.

The following risk factors were evaluated: 1) patient demographics and admission characteristics (age, sex, admission unit, Charlson comorbidity score, days of hospitalization prior to ICU admission, and admission platelet, hemoglobin, and leukocyte counts), 2) pre-existing comorbidities (alcoholism, liver cirrhosis, hypersplenism, rheumatoid disease, chronic renal failure, and hematologic and non-hematologic cancer), 3) acquired risk factors (acute hepatitis, deep vein thrombosis and pulmonary embolism, diagnosis of lupus, gastrointestinal bleeding, and sepsis during the ICU stay), and 4) procedures associated with thrombocytopenia (coronary artery bypass grafting, extracorporeal circulation, hemodialysis, intraaortic balloon pump, mechanical ventilation, blood transfusions, splenectomy). ${ }^{2}$ In order to evaluate risk factors for ICU-acquired thrombocytopenia in patients who were not suffering from diseases highly associated with thrombocytopenia, we evaluated risk factors in a model excluding patients suffering from the following diseases highly associated with thrombocytopenia: disseminated intravascular coagulation, thrombotic thrombocytopenic purpura, microangiopathies, heparin-induced thrombocytopenia, 
aplastic anemia and other bone marrow failures, and secondary thrombocytopenia (includes post-transfusion, dilutional, drug-induced, extracorporeal circulation-induced, and massive blood transfusion and platelet alloimmunization-induced thrombocytopenia). ${ }^{33}$ Multivariable logistic regression was used for this analysis. Since univariable analyses were used to screen variables rather than to test a specific hypothesis, all factors with a $P$ value $<0.2$ in the univariable analysis were included in the multivariable logistic regression model and reduced using a backward elimination procedure. Variables were selected for removal by using a $P$ value of 0.05 as the significance level. The discriminative power of the logistic equation was estimated with the $c$ statistic, and the adequacy was tested for goodness of fit with the Hosmer-Lemeshow statistic (ten groups). Conformity with the linear gradient of each continuous variable was checked. Following this analysis, admission platelet counts were categorized. Multicollinearity between variables in the models was verified using variance inflation factors, and influential cases were verified.

The independent effect of thrombocytopenia on mortality was evaluated using a multivariable regression model that included the admission diagnostic categories: age, sex, admission unit, length of ICU stay, length of stay before ICU admission, number of ICU stays, mechanical ventilation, sepsis, major bleeding, and Charlson comorbidity scores. Adjusted mortality was also calculated in each diagnostic category. Finally, the independent effect of thrombocytopenia on major bleeding was evaluated in a multivariable analysis adjusting for age, sex, admission unit, Charlson comorbidity scores, mechanical ventilation, extracorporeal circulation, dialysis, sepsis, and moderate to severe liver dysfunction. All reported $P$ values are twosided. Statistical analysis was performed with $\mathrm{PASW}^{\circledR}$ version 18.0 (SPSS Inc., Chicago, Il, USA).

\section{Results}

During the study period, 20,775 patients were identified as eligible for inclusion in the study. Seventy-nine patients had incomplete data and were excluded from the study (Figure); thus, 20,696 cardiac, medical, surgical, or trauma critically ill patients were included in the study. Prevalent and incident thrombocytopenia occurred in $13.3 \%$ and $7.8 \%$ of patients, respectively, and thrombocytopenia was severe in $3.5 \%$ and $1.0 \%$ of prevalent and incident cases, respectively. In patients with incident thrombocytopenia, thrombocytopenia developed from one to 60 days following ICU admission with a median $\left[25^{\text {th }}-75^{\text {th }}\right.$ percentile $]$ of 2.2 [1.3-3.3] days after ICU admission.
Patients with prevalent and incident thrombocytopenia were slightly older and spent more days in hospital prior to ICU admission than those who didn't develop thrombocytopenia (Table 1). Patients with prevalent and incident thrombocytopenia were more likely to have been given mechanical ventilation. The Charlson comorbidity index was slightly lower in patients with prevalent thrombocytopenia and slightly higher in patients with incident thrombocytopenia compared with patients without thrombocytopenia. Compared with patients without thrombocytopenia, those with prevalent thrombocytopenia were more often admitted for valvular, vascular, infectious, and hematological diseases, whereas those with incident thrombocytopenia were more often admitted for vascular, valvular, genitourinary, and infectious diseases.

From the univariable analysis, we identified 24 variables for inclusion in the multivariable analysis (Table 2). Independent risk factors for ICU-acquired thrombocytopenia included age, female sex, admission to the surgical and medical units, admission platelet counts, admission hemoglobin, mechanical ventilation, length of hospital stay prior to ICU admission, liver cirrhosis, hypersplenism, coronary bypass grafting, intra-aortic balloon pump placement, acute hepatitis, septic shock, pulmonary embolism, and deep vein thrombosis (Table 3). The discriminative power of the model was excellent (c-statistic = 0.83), but the Hosmer-Lemeshow test suggested that the model was not well calibrated $\left(\mathrm{Khi}^{2}=47.7 ; P<0.001\right)$. The lack of fit occurred predominately in the first and last three deciles (Appendix 2).

The incidence of positive heparin platelet factor 4 antibodies associated with thrombocytopenia in the prevalent and incident cases was $0.3 \%$ (nine cases) and $1.5 \%$ (24 cases), respectively. Thrombocytopenia was classified as secondary thrombocytopenia in $2.9 \%$ (80 cases) and $4.2 \%$ (68 cases) of prevalent and incident cases, respectively.

Prevalent and incident thrombocytopenia were both associated with prolonged ICU length of stay (median $\left[25^{\text {th }}-75^{\text {th }}\right.$ percentile]) $(4.0$ [2.9-6.8] days and 6.1 [3.8-11.2] days, respectively) compared with patients without thrombocytopenia (3.4 [2.6-5.2] days; $P<0.001$ for both comparisons). Major bleeding during the index hospitalization was also more frequent in patients with prevalent or incident thrombocytopenia when compared with patients without thrombocytopenia $(20.3 \%$ vs $19.3 \%$ vs $12.5 \%$, respectively; $P<0.001$ for both comparisons). The association between thrombocytopenia (prevalent or incident) and major bleeding remained significant after adjustment for age, sex, admission unit, Charlson comorbidity scores, mechanical ventilation, extracorporeal circulation, dialysis, sepsis, and moderate to severe liver dysfunction [adjusted 
Figure Study flow chart. ICU $=$ intensive care unit

20775 Adult patients with

ICU admissions $>48$ hours

between 1997-2011

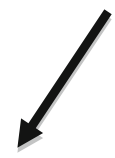

79 patients with no platelet count in first 24 hours of admission excluded

20696 patients

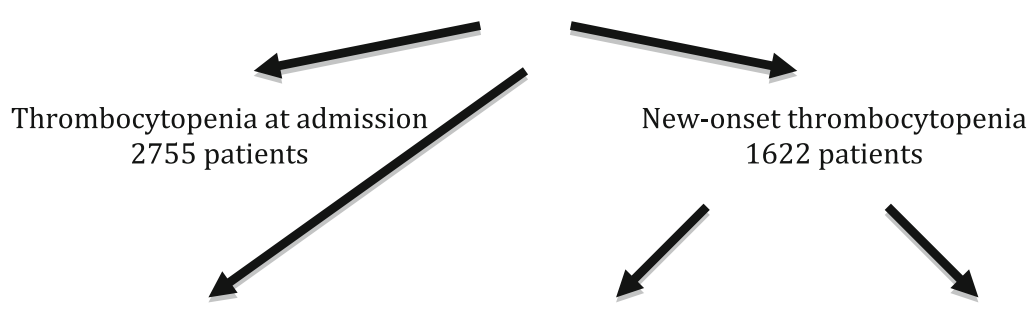

15252 included in the

risk factor analysis

for incident thrombocytopenia
1359 included in the risk factor analysis

for incident thrombocytopenia
263 with diseases highly associated with thrombocytopenia excluded odds ratio (aOR) $1.32 ; 95 \%$ confidence interval (CI) 1.20 to 1.46; $P<0.001]$.

Prevalent and incident thrombocytopenia were associated with mortality rates of $14.3 \%$ and $24.7 \%$, respectively, compared with $10.2 \%$ in patients without thrombocytopenia $(P<0.001$ for both comparisons $)$. Moderate and severe thrombocytopenia were associated with mortality rates of $13.9 \%$ and $33.5 \%$, respectively $(P<0.001$ for both comparisons). Severe thrombocytopenia was associated with mortality rates of $29.7 \%$ and $44.5 \%$ in patients with prevalent and incident thrombocytopenia, respectively ( $P<0.001$ for both comparisons). After adjusting for admission categories, age, sex, admission unit, length of ICU stay, length of stay before ICU admission, number of ICU stays, sepsis, major bleeding, and Charlson scores, thrombocytopenia remained associated with an increased risk of mortality (aOR 1.25; 95\% CI 1.20 to 1.31; $P<0.001)$.

The greatest impact of thrombocytopenia on mortality was observed in the cancer, digestive, genitourinary, respiratory, vascular, infectious, trauma/injury, and circulatory/cardiac diagnoses (Table 4).

\section{Discussion}

In this study of thrombocytopenia in critically ill cardiac, medical, surgical, and trauma patients, we found that $13.3 \%$ of patients had at least one platelet count $<100 \times 10^{9} \cdot \mathrm{L}^{-1}$ on ICU admission day and that an additional $7.8 \%$ developed thrombocytopenia later in the ICU stay. Severe thrombocytopenia was relatively rare but more frequent on admission than during the ICU stay. Previous studies have reported different results concerning the epidemiology of thrombocytopenia in the ICU, with a reported prevalence of thrombocytopenia as high as $20.0 \%, 23.4 \%$, and $27.1 \%$ using the same threshold of platelet count. ${ }^{8,13,22}$ Dissimilar patient populations and greater severity of disease than were found in our study may account for this difference. On the other hand, the incidence of thrombocytopenia in previous studies is similar to our findings. One study in a surgical ICU population reported an incidence of $13.0 \% .^{12}$ Studies using a more inclusive definition of thrombocytopenia (platelets $<150 \times 10^{9} \cdot \mathrm{L}^{-1}$ ) have reported an incidence varying from $14.3-44.1 \% .^{3,5,8}$ Thrombocytopenia was associated with an increase in length of stay and bleeding events, and the association with major bleeding remained positive after multivariable adjustment. Previous studies in critically ill patients have reported an association between thrombocytopenia and bleeding events but have not adjusted for disease severity. ${ }^{2}$ Our study used an inclusive definition of bleeding and could not evaluate the onset of bleeding in relation to thrombocytopenia because of the limits of ICD coding; however, in prevalent cases and in a majority of incident cases, thrombocytopenia occurred early in the ICU stay. 
Table 1 Characteristics of the 20,696 study patients

\begin{tabular}{|c|c|c|c|}
\hline & $\begin{array}{l}\text { No thrombocytopenia } \\
(n=16,319)\end{array}$ & $\begin{array}{l}\text { Prevalent } \\
(n=2,755)\end{array}$ & $\begin{array}{l}\text { Incident } \\
(n=1,622)\end{array}$ \\
\hline Age, yr (SD) & $64.5(15.3)$ & $65.1(14.2)$ & $66.4(13.8)$ \\
\hline Male sex & $60.8 \%$ & $62.4 \%$ & $64.4 \%$ \\
\hline $\begin{array}{l}\text { Median days hospitalized before ICU admission } \\
{\left[25^{\text {th }}-75^{\text {th }} \text { percentile }\right]}\end{array}$ & $1.0[0-2.0]$ & $1.0[1.0-7.0]$ & $1.0[0-6.0]$ \\
\hline Median number of ICU admissions $\left[25^{\text {th }}-75^{\text {th }}\right.$ percentile $]$ & $1.0[0-2.0]$ & $1.0[1.0-7.0]$ & $1.0[0-6.0]$ \\
\hline Median Charlson score $\left[25^{\text {th }}-75^{\text {th }}\right.$ percentile $]$ & $2.0[1.0-4.0]$ & $2.0[1.0-4.0]$ & $2.0[1.0-4.0]$ \\
\hline Platelet count admission day $\left(\times 10^{9} \cdot \mathrm{L}^{-1}\right)(\mathrm{SD})$ & $253(97)$ & $142(77)$ & $193(76)$ \\
\hline Hemoglobin admission day $\left(\times 10^{6} \cdot \mathrm{L}^{-1}\right)(\mathrm{SD})$ & $122(24)$ & $111(25)$ & $119(25)$ \\
\hline Leukocyte count admission day $\left(\times 10^{6} \cdot \mathrm{L}^{-1}\right)(\mathrm{SD})$ & $11.5(6.5)$ & $8.9(10.2)$ & $11.8(9.1)$ \\
\hline Medical/Coronary ICU & $47.9 \%$ & $26.9 \%$ & $51.1 \%$ \\
\hline Surgical ICU & $28.0 \%$ & $63.8 \%$ & $38.0 \%$ \\
\hline Mixed unit & $21.9 \%$ & $9.0 \%$ & $10.4 \%$ \\
\hline Mechanical ventilation & $25.7 \%$ & $58.3 \%$ & $56.1 \%$ \\
\hline \multicolumn{4}{|l|}{ Admission diagnostics categories } \\
\hline Cancer & $8.8 \%$ & $7.3 \%$ & $5.1 \%$ \\
\hline Circulatory/Cardiac & $43.1 \%$ & $31.6 \%$ & $38.2 \%$ \\
\hline Digestive & $7.5 \%$ & $7.2 \%$ & $8.7 \%$ \\
\hline Genitourinary & $2.1 \%$ & $1.9 \%$ & $3.1 \%$ \\
\hline Hematological & $0.2 \%$ & $1.2 \%$ & $0.4 \%$ \\
\hline Infectious & $2.1 \%$ & $3.5 \%$ & $4.0 \%$ \\
\hline Musculoskeletal & $1.5 \%$ & $1.0 \%$ & $1.5 \%$ \\
\hline Neurological & $7.2 \%$ & $2.2 \%$ & $4.4 \%$ \\
\hline Respiratory & $8.9 \%$ & $3.8 \%$ & $5.9 \%$ \\
\hline Trauma/Injury & $7.8 \%$ & $6.4 \%$ & $9.1 \%$ \\
\hline Valvular & $2.1 \%$ & $21.4 \%$ & $7.4 \%$ \\
\hline Vascular & $6.2 \%$ & $11.1 \%$ & $10.2 \%$ \\
\hline Other & $2.2 \%$ & $1.2 \%$ & $1.7 \%$ \\
\hline
\end{tabular}

ICU = intensive care unit; $\mathrm{SD}=$ standard deviation

After adjusting for disease severity, admission categories, and comorbidities, thrombocytopenia remained independently associated with an increased risk of in-hospital mortality (OR 1.25 ; 95\% CI 1.20 to $1.31 ; P<0.001$ ). This finding confirms the independent association reported in other studies. ${ }^{5,8,23}$ These studies reported odds ratios greater than ours for hospital or ICU mortality, which varied from 2.20-3.10. This difference may be due to differences in patient populations, as our study also included cardiac ICU patients. It remains unclear whether this effect on mortality is due to disease severity and possible residual confounding from unknown factors or is related to the essential role platelets play in many disease processes. ${ }^{34} \mathrm{~A}$ growing body of evidence suggests that platelets might not only be executors of thrombosis but might also be important actors in the immune response. ${ }^{34,35}$

Critically ill patients are a heterogeneous patient population in which the impact of thrombocytopenia may vary widely depending on the associated diseases. We observed that thrombocytopenia had the greatest impact on mortality after adjustments in patients admitted for cancer, genitourinary, digestive, respiratory, vascular, and infectious diagnoses. In other diagnostic categories, such as neurological and musculoskeletal diseases, the impact of thrombocytopenia on mortality seems less important. Accordingly, thrombocytopenia may be linked to advanced stages of diseases, such as cancer or liver cirrhosis, and to more severe presentations of diseases, such as urinary tract and respiratory infections. Thrombocytopenia may also be associated with an increased risk of complications, such as bleeding or secondary infections, in these identified diagnostic categories more than in others. The increased risk of mortality associated with thrombocytopenia in cancer patients, specifically, may also be due to an association with recent chemotherapy or more advanced cancer. In our study, cancer in patients admitted to the ICU had the greatest impact on mortality associated with thrombocytopenia. These findings are corroborated by a recent study 
Table 2 Univariable analysis of risk factors for ICU-acquired thrombocytopenia $(n=16,636$; \#events $=1,359$ )
$\mathrm{OR}=$ odds ratio;

$\mathrm{CI}=$ confidence interval;

$\mathrm{ICU}=$ intensive care unit

\begin{tabular}{|c|c|c|}
\hline Variables & OR $(95 \% \mathrm{CI})$ & $P$ value \\
\hline \multicolumn{3}{|l|}{ Demographic and admission characteristics } \\
\hline Age & $1.010(1.006$ to 1.014$)$ & $<0.001$ \\
\hline Sex (female) & $0.83(0.74$ to 0.93$)$ & 0.002 \\
\hline Medical ICU admission & $1.05(0.94$ to 1.17$)$ & 0.39 \\
\hline Surgical ICU admission & $1.74(1.55$ to 1.95$)$ & $<0.001$ \\
\hline Mixed ICU & $0.38(0.31$ to 0.46$)$ & $<0.001$ \\
\hline Charlson comorbidity score & $1.03(1.00$ to 1.05$)$ & 0.02 \\
\hline Days of hospitalization prior to ICU admission & 1.02 (1.01 to 1.02$)$ & $<0.001$ \\
\hline Admission platelet counts & $0.989(0.988$ to 0.990$)$ & $<0.001$ \\
\hline Admission hemoglobin & $0.994(0.992$ to 0.996$)$ & $<0.001$ \\
\hline Admission leukocyte counts & 1.005 (0.997 to 1.012$)$ & 0.24 \\
\hline \multicolumn{3}{|l|}{ Pre-existing comorbidities } \\
\hline Alcoholism & $1.42(1.06$ to 1.92$)$ & 0.02 \\
\hline Liver cirrhosis & $2.46(1.74$ to 3.50$)$ & $<0.001$ \\
\hline Hypersplenism & 8.45 (1.89 to 37.8$)$ & 0.005 \\
\hline Rheumatoid disease & $0.92(0.64$ to 1.32$)$ & 0.64 \\
\hline Chronic renal failure & $1.16(0.92$ to 1.47$)$ & 0.21 \\
\hline Hematologic cancer & $1.60(0.94$ to 2.71$)$ & 0.08 \\
\hline Non-hematologic cancer & $0.70(0.53$ to 0.94$)$ & 0.02 \\
\hline \multicolumn{3}{|l|}{ Acquired risk factors } \\
\hline Acute hepatitis & $2.22(1.37$ to 3.60$)$ & 0.001 \\
\hline Deep vein thrombosis and pulmonary embolism & 1.33 (1.06 to 1.68$)$ & 0.02 \\
\hline Diagnosis of lupus & $2.51(1.16$ to 5.40$)$ & 0.02 \\
\hline Gastrointestinal bleeding & $2.77(1.71$ to 4.48$)$ & $<0.001$ \\
\hline Sepsis & 2.44 (1.96 to 3.04$)$ & $<0.001$ \\
\hline \multicolumn{3}{|l|}{ Procedures } \\
\hline Coronary artery bypass grafting & $4.02(3.49$ to 4.64$)$ & $<0.001$ \\
\hline Extracorporeal circulation & $3.75(3.24$ to 4.34$)$ & $<0.001$ \\
\hline Hemodialysis & $1.32(1.02$ to 1.72$)$ & 0.04 \\
\hline Intra-aortic balloon pump & $3.75(3.07$ to 4.58$)$ & $<0.001$ \\
\hline Mechanical ventilation & 2.47 (2.19 to 2.78$)$ & $<0.001$ \\
\hline Blood transfusions & $4.15(3.71$ to 4.65$)$ & $<0.001$ \\
\hline Splenectomy & $2.69(0.41$ to 17.61$)$ & 0.30 \\
\hline
\end{tabular}

of metastatic cancer patients admitted to ICU that identified thrombocytopenia (OR 26.2) as an important predictor of mortality. ${ }^{36}$ Hence, patients admitted within these diagnostic categories may represent potential subgroups for interventional trials of strategies with the objective of modifying the impact of thrombocytopenia and conditions leading to thrombocytopenia-related mortality.

The purpose of this study was to verify independent risk factors for thrombocytopenia, such as admitting platelet counts, sepsis, and intra-aortic balloon pump, which had been described in previous studies. ${ }^{2-4,9,13,37}$ Given the large sample size and important number of candidate factors, new factors were identified in this study which had not been previously described, including history of liver cirrhosis, admission hemoglobin, and new pulmonary embolism or deep vein thrombosis. The hospital admission unit was also an important factor, as admission to the surgical ICU and, to a lesser extent, the medical ICU was associated with an increased risk of thrombocytopenia. Invasive surgery and severity of disease may have accounted for these findings. In order to evaluate risk factors for ICU-acquired thrombocytopenia in patients who were not suffering from diseases highly associated with thrombocytopenia, we chose to exclude patients suffering from disseminated intravascular coagulation, thrombotic microvascular disorders, and myelodysplasia.

Our model showed excellent discriminative power, but calibration was non-optimal. It remains uncertain how much of the lack of fit is due to the model and how much is due to the sensitivity of the Hosmer-Lemeshow test to large 
Table 3 Multivariable analysis of risk factors for ICU-acquired thrombocytopenia ( $n=16,621$, \#events 1,359)
$\mathrm{OR}=$ odds ration;

$\mathrm{CI}=$ confidence interval;

ICU $=$ intensive care unit

\begin{tabular}{|c|c|c|}
\hline Variables & Adjusted OR $(95 \% \mathrm{CI})$ & $P$ value \\
\hline Age (per yr) & $1.007(1.002$ to 1.012$)$ & 0.002 \\
\hline Female sex & $1.18(1.03$ to 1.35$)$ & 0.02 \\
\hline \multicolumn{3}{|l|}{ Admission unit } \\
\hline Medical ICU admission & $1.58(1.27$ to 1.95$)$ & $<0.001$ \\
\hline Surgical ICU admission & 1.69 (1.35 to 2.12$)$ & 0.001 \\
\hline Mixed ICU & 1.00 & \\
\hline Days of hospitalization prior to ICU admission & $1.012(1.007$ to 1.016$)$ & $<0.001$ \\
\hline Mechanical ventilation & 1.95 (1.71 to 2.30$)$ & $<0.001$ \\
\hline \multicolumn{3}{|l|}{ Admitting platelet count } \\
\hline $100-149 \times 10^{9} \cdot \mathrm{L}^{-1}$ & $24.57(15.94$ to 37.88$)$ & $<0.001$ \\
\hline $150-199 \times 10^{9} \cdot \mathrm{L}^{-1}$ & $6.72(4.38$ to 10.30$)$ & $<0.001$ \\
\hline $200-249 \times 10^{9} \cdot \mathrm{L}^{-1}$ & $3.26(2.12$ to 5.03$)$ & $<0.001$ \\
\hline $250-299 \times 10^{9} \cdot \mathrm{L}^{-1}$ & $2.52(1.61$ to 3.93$)$ & $<0.001$ \\
\hline $300-349 \times 10^{9} \cdot \mathrm{L}^{-1}$ & $1.56(0.94$ to 2.59$)$ & 0.09 \\
\hline $350-399 \times 10^{9} \cdot \mathrm{L}^{-1}$ & 1.48 (0.82 to 2.67$)$ & 0.19 \\
\hline$>400 \times 10^{9} \cdot \mathrm{L}^{-1}$ & 1.00 & \\
\hline Admitting hemoglobin (per $\mathrm{g} \cdot \mathrm{L}^{-1}$ ) & $1.006(1.003$ to 1.009$)$ & $<0.001$ \\
\hline Liver cirrhosis & 2.01 (1.34 to 3.05$)$ & 0.001 \\
\hline Hypersplenism & $6.65(1.17$ to 37.73$)$ & 0.03 \\
\hline Blood transfusion & 3.06 (2.66 to 3.52$)$ & $<0.001$ \\
\hline Intra-aortic balloon pump & 2.47 (1.93 to 3.15$)$ & $<0.001$ \\
\hline Coronary bypass grafting & 2.83 (2.37 to 3.37$)$ & $<0.001$ \\
\hline Septic shock & $2.60(2.03$ to 3.33$)$ & $<0.001$ \\
\hline Acute hepatitis & $2.21(1.27$ to 3.85$)$ & $<0.001$ \\
\hline Pulmonary embolism and deep vein thrombosis & $1.53(1.19$ to 1.98$)$ & 0.001 \\
\hline
\end{tabular}

sample sizes. ${ }^{38}$ Although heparin-induced thrombocytopenia is frequently suspected in critically ill patients with thrombocytopenia, the incidence of heparin platelet factor 4 antibodies was relatively low in patients with thrombocytopenia in our cohort. This finding could be explained by underdiagnosis, or it could represent an institutional variability in requests for heparin platelet factor 4 antibodies. The use of the PF4/heparin ELISA test, which has a limited specificity to define heparin-induced thrombocytopenia, may also have identified false positive cases. Nevertheless, previous studies of medical surgical critical care patients have reported a similar incidence of heparin-induced thrombocytopenia. $^{39,40}$

Even though this study includes a large sample size and a considerable number of variables were analyzed, it has some limitations. The retrospective design limits the information that can be obtained concerning possible etiologies for the thrombocytopenia. The use of ICD and CCDATC codes to classify diagnostic categories and identify risk factors also has a number of limits. Certain consumptive causes of thrombocytopenia, such as druginduced thrombocytopenia, were not evaluated.
Information bias secondary to misclassification is a concern but would most likely be non-differential. The retrospective design also limited the available data concerning Glasgow coma scales, thus precluding the use of severity of illness scores, such as the APACHE II score and other population-specific scores. In addition, due to the problems associated with automated variable selection procedures, some of the newly identified predictors may be spurious or their effects may be overestimated and would need to be confirmed in other studies. ${ }^{41}$

In conclusion, thrombocytopenia, defined as a platelet count $<100 \times 10^{9} \cdot \mathrm{L}^{-1}$ is common both upon admission and during ICU stay in medical, surgical, and trauma ICU patients. Prevalent thrombocytopenia and incident thrombocytopenia are both associated with prolonged ICU length of stay and major bleeding. In addition, thrombocytopenia is associated with an independent risk of mortality. The greatest impact of thrombocytopenia on mortality was observed in the cancer, genitourinary, digestive, vascular, infectious, and respiratory diagnostic categories. Independent predictors of thrombocytopenia included age, female sex, age, admission platelet counts, admission hemoglobin, 
Table 4 Comparative hospital mortality in patients with and without thrombocytopenia according to admission diagnostic category

\begin{tabular}{|c|c|c|c|c|}
\hline \multirow{2}{*}{$\begin{array}{l}\text { Admission diagnosis }(n=20,252 \text {, \# events } \\
2,405)\end{array}$} & \multicolumn{2}{|l|}{ Hospital mortality } & \multirow{2}{*}{$\begin{array}{l}\text { Crude OR; } P \text { value } \\
(95 \% \mathrm{CI})\end{array}$} & \multirow{2}{*}{$\begin{array}{l}\text { Adjusted OR; } P \text { value } \\
(95 \% \mathrm{CI})\end{array}$} \\
\hline & $\begin{array}{l}\text { No } \\
\text { thrombocytopenia }\end{array}$ & Thrombocytopenia & & \\
\hline Hematological (67) & $10.7 \%$ & $15.4 \%$ & $\begin{array}{l}1.51 ; P=0.58(0.35 \text { to } \\
\quad 6.66)\end{array}$ & $\begin{array}{l}0.49 ; P=0.53(0.05 \text { to } \\
\quad 4.53)\end{array}$ \\
\hline Circulatory $(8,538)$ & $7.1 \%$ & $12.1 \%$ & $\begin{array}{l}1.79 ; P<0.001(1.50 \text { to } \\
2.15)\end{array}$ & $\begin{array}{l}1.54 ; P<0.001(1.23 \text { to } \\
1.91)\end{array}$ \\
\hline Valvular $(1,051)$ & $7.6 \%$ & $8.5 \%$ & $\begin{array}{l}1.12 ; P=0.63(0.70 \text { to } \\
1.82)\end{array}$ & $\begin{array}{l}1.74 ; P=0.06(0.98 \text { to } \\
\quad 3.10)\end{array}$ \\
\hline Digestive $(1,566)$ & $11.1 \%$ & $29.7 \%$ & $\begin{array}{l}3.39 ; P<0.001 \text { ( } 2.53 \text { to } \\
5.54)\end{array}$ & $\begin{array}{l}2.52 ; P<0.001(1.83 \text { to } \\
\quad 3.48)\end{array}$ \\
\hline Genitourinary (449) & $11.0 \%$ & $27.5 \%$ & $\begin{array}{l}3.08 ; P<0.001 \text { (1.78 to } \\
\quad 5.33)\end{array}$ & $\begin{array}{l}2.42 ; P=0.006(1.29 \text { to } \\
\quad 4.54)\end{array}$ \\
\hline Vascular $(1,483)$ & $7.5 \%$ & $15.9 \%$ & $\begin{array}{l}2.32 ; P<0.001(1.65 \text { to } \\
\quad 3.27)\end{array}$ & $\begin{array}{l}2.07 ; P<0.001(1.38 \text { to } \\
\quad 3.11)\end{array}$ \\
\hline Cancer $(1,725)$ & $11.2 \%$ & $39.7 \%$ & $\begin{array}{l}5.21 ; P<0.001 \text { (3.90 to } \\
\quad 6.96)\end{array}$ & $\begin{array}{l}3.71 ; P<0.001 \text { (2.65 to } \\
5.19)\end{array}$ \\
\hline Central nervous system $(1,310)$ & $18.8 \%$ & $26.7 \%$ & $\begin{array}{l}1.57 ; P=0.03(1.04 \text { to } \\
2.38)\end{array}$ & $\begin{array}{l}1.25 ; P=0.335(0.79 \text { to } \\
1.97)\end{array}$ \\
\hline Musculoskeletal (300) & $10.1 \%$ & $21.2 \%$ & $\begin{array}{l}2.39 ; P=0.03(1.09 \text { to } \\
5.24)\end{array}$ & $1.08 ; P=0.89(0.39-2.96)$ \\
\hline Trauma/Injury $(1,595)$ & $8.7 \%$ & $16.4 \%$ & $\begin{array}{l}2.05 ; P<0.001(1.44 \text { to } \\
2.92)\end{array}$ & $\begin{array}{l}1.65 ; P=0.01(1.11 \text { to } \\
2.45)\end{array}$ \\
\hline Respiratory $(1,655)$ & $18.3 \%$ & $35.6 \%$ & $\begin{array}{l}2.47 ; P<0.001 \text { ( } 1.80 \text { to } \\
\text { 3.39) }\end{array}$ & $\begin{array}{l}2.56 ; P<0.001 \text { ( } 1.80 \text { to } \\
3.66)\end{array}$ \\
\hline Infectious (513) & $15.7 \%$ & $30.9 \%$ & $\begin{array}{l}2.40 ; P<0.001 \text { (1.55 to } \\
\quad 3.73)\end{array}$ & $\begin{array}{l}2.05 ; P=0.004(1.25 \text { to } \\
\quad 3.37)\end{array}$ \\
\hline
\end{tabular}

$\mathrm{OR}=$ odds ratio $; \mathrm{CI}=$ confidence interval

mechanical ventilation, length of hospital stay prior to ICU admission, liver cirrhosis, hypersplenism, coronary bypass grafting, intra-aortic balloon pump placement, acute hepatitis, septic shock, pulmonary embolism, and deep vein thrombosis.

Funding Fonds de recherche en Santé du Québec.

Competing interests None declared.

\section{Appendix 1: Search strategy for identification of risk factors}

MEDLINE search terms used to identify studies evaluating thrombocytopenia risk factor

1. critical care.mp. or exp Critical Care/

2. intensive care unit.mp. or Intensive Care Units/

3. critical illness.mp. or Critical Illness/

4. 1 or 2 or 3

5. exp Thrombocytopenia/ or thrombocytopenia.mp.

6. blood platelet.mp. or Blood Platelets/

7. thrombocyte.mp

8. 5 or 6 or 7

\section{4 and 8}

Bibliographies of relevant citations and reviews were also searched.

\section{Appendix 2: Hosmer-Lemeshow goodness of fit test C-statistic results}

\begin{tabular}{|c|c|c|c|c|c|}
\hline \multirow[t]{2}{*}{$\begin{array}{l}\text { Subgroups } \\
(\mathrm{n} / 10)\end{array}$} & \multicolumn{2}{|c|}{$\begin{array}{l}\text { Thrombocytopenia }=\text { NON } \\
\text { CASES }\end{array}$} & \multicolumn{2}{|c|}{ Thrombocytopenia $=$ CASES } & \multirow[t]{2}{*}{ Total } \\
\hline & Observations & Expected & Observations & Expected & \\
\hline 1 & 1,648 & $1,646,295$ & 14 & 15,705 & 1,662 \\
\hline 2 & 1,647 & $1,636,389$ & 15 & 25,611 & 1,662 \\
\hline 3 & 1,641 & $1,627,261$ & 21 & 34,739 & 1,662 \\
\hline 4 & 1,637 & $1,619,181$ & 25 & 42,819 & 1,662 \\
\hline 5 & 1,621 & $1,607,667$ & 41 & 54,333 & 1,662 \\
\hline 6 & 1,584 & $1,584,912$ & 78 & 77,088 & 1,662 \\
\hline 7 & 1,559 & $1,562,493$ & 103 & 99,507 & 1,662 \\
\hline 8 & 1,465 & $1,503,398$ & 197 & 158,602 & 1,662 \\
\hline 9 & 1,350 & $1,402,056$ & 312 & 259,944 & 1,662 \\
\hline 10 & 1,110 & $1,072,349$ & 553 & 590,651 & 1,663 \\
\hline
\end{tabular}




\section{References}

1. Chakraverty R, Davidson S, Peggs $K$, Stross P, Garrard C, Littlewood TJ. The incidence and cause of coagulopathies in an intensive care population. Br J Haematol 1996; 93: 460-3.

2. Hui P, Cook DJ, Lim W, Fraser GA, Arnold DM. The frequency and clinical significance of thrombocytopenia complicating critical illness: a systematic review. Chest 2011; 139: 271-8.

3. Crowther MA, Cook DJ, Meade MO, et al. Thrombocytopenia in medical-surgical critically ill patients: prevalence, incidence, and risk factors. J Crit Care 2005; 20: 348-53.

4. Ben Hamida C, Lauzet JY, Rezaiguia-Delclaux $S$, et al. Effect of severe thrombocytopenia on patient outcome after liver transplantation. Intensive Care Med 2003; 29: 756-62.

5. Vanderschueren $S$, De Weerdt A, Malbrain M, et al. Thrombocytopenia and prognosis in intensive care. Crit Care Med 2000; 28: 1871-6.

6. Nydam TL, Kashuk JL, Moore EE, et al. Refractory postinjury thrombocytopenia is associated with multiple organ failure and adverse outcomes. J Trauma 2011; 70: 401-6; discussion 406-7.

7. Stephan F, de Montblanc J, Cheffi A, Bonnet F. Thrombocytopenia in critically ill surgical patients: a case-control study evaluating attributable mortality and transfusion requirements. Crit Care 1999; 3: 151-8.

8. Vandijck DM, Blot SI, De Waele JJ, Hoste EA, Vandewoude KH, Decruyenaere JM. Thrombocytopenia and outcome in critically ill patients with bloodstream infection. Heart Lung 2010; 39: 21-6.

9. Strauss $R$, Wehler M, Mehler K, Kreutzer D, Koebnick C, Hahn $E G$. Thrombocytopenia in patients in the medical intensive care unit: bleeding prevalence, transfusion requirements, and outcome. Crit Care Med 2002; 30: 1765-71.

10. Cherif H, Martling CR, Hansen J, Kalin M, Bjorkholm M. Predictors of short and long-term outcome in patients with hematological disorders admitted to the intensive care unit for a life-threatening complication. Support Care Cancer 2007; 15: 1393-8.

11. Shalansky SJ, Verma AK, Levine M, Spinelli JJ, Dodek PM. Risk markers for thrombocytopenia in critically ill patients: a prospective analysis. Pharmacotherapy 2002; 22: 803-13.

12. Cawley MJ, Wittbrodt ET, Boyce EG, Skaar DJ. Potential risk factors associated with thrombocytopenia in a surgical intensive care unit. Pharmacotherapy 1999; 19: 108-13.

13. Baughman RP, Lower EE, Flessa HC, Tollerud DJ. Thrombocytopenia in the intensive care unit. Chest 1993; 104: 1243-7.

14. Sharma B, Sharma M, Majumder M, Steier W, Sangal A, Kalawar $M$. Thrombocytopenia in septic shock patients-a prospective observational study of incidence, risk factors and correlation with clinical outcome. Anaesth Intensive Care 2007; 35: 874-80.

15. Hanes $S D$, Quarles DA, Boucher BA. Incidence and risk factors of thrombocytopenia in critically ill trauma patients. Ann Pharmacother 1997; 31: 285-9.

16. Grant A, Moshyk A, Diab $H$, et al. Integrating feedback from a clinical data warehouse into practice organisation. Int $\mathrm{J}$ Med Inform 2006; 75: 232-9.

17. Lamontagne F, Garant MP, Carvalho JC, Lanthier L, Smieja M, Pilon D. Pneumococcal vaccination and risk of myocardial infarction. CMAJ 2008; 179: 773-7.

18. Aris A. Endometriosis-associated ovarian cancer: a ten-year cohort study of women living in the Estrie Region of Quebec. Canada. J Ovarian Res 2010; 3: 2.

19. Carignan A, Allard C, Pepin J, Cossette B, Nault V, Valiquette L. Risk of Clostridium difficile infection after perioperative antibacterial prophylaxis before and during an outbreak of infection due to a hypervirulent strain. Clin Infect Dis 2008; 46: 1838-43.
20. Cossette B, Pelletier ME, Carrier N, et al. Evaluation of bleeding risk in patients exposed to therapeutic unfractionated or lowmolecular-weight heparin: a cohort study in the context of a quality improvement initiative. Ann Pharmacother 2010; 44: 994-1002.

21. Lambert L, Blais C, Hamel D, et al. Evaluation of care and surveillance of cardiovascular disease: can we trust medicoadministrative hospital data? Can J Cardiol 2012; 28: 162-8.

22. Bonfiglio MF, Traeger SM, Kier KL, Martin BR, Hulisz DT, Verbeck SR. Thrombocytopenia in intensive care patients: a comprehensive analysis of risk factors in 314 patients. Ann Pharmacother 1995; 29: 835-42.

23. Stephan F, Hollande J, Richard O, Cheffi A, Maier-Redelsperger $M$, Flahault A. Thrombocytopenia in a surgical ICU. Chest 1999; 115: 1363-70.

24. Drews RE, Weinberger SE. Thrombocytopenic disorders in critically ill patients. Am J Respir Crit Care Med 2000; 162: 347-51.

25. George JN, Rivzi MA. Diagnosis and management of thrombocytopenia. In: Colman RW, Hirsh J, Marder VJ, Clowes AW, George JN, editors. Hemostasis and Thrombosis: Basic Principles and Clinical Practice. 4th ed. Philadelphia: Lippincott Williams \& Wilkins; 2001. p. 1021-9.

26. Charlson ME, Pompei P, Ales KL, MacKenzie CR. A new method of classifying prognostic comorbidity in longitudinal studies: development and validation. J Chronic Dis 1987; 40: 373-83.

27. Deyo RA, Cherkin DC, Ciol MA. Adapting a clinical comorbidity index for use with ICD-9-CM administrative databases. J Clin Epidemiol 1992; 45: 613-9.

28. Quan H, Parsons GA, Ghali WA. Validity of information on comorbidity derived rom ICD-9-CCM administrative data. Med Care 2002; 40: 675-85.

29. Li B, Evans D, Faris $P$, Dean $S$, Quan $H$. Risk adjustment performance of Charlson and Elixhauser comorbidities in ICD-9 and ICD-10 administrative databases. BMC Health Serv Res 2008; 8: 12.

30. Quach S, Hennessy DA, Faris P, Fong A, Quan H, Doig C. A comparison between the APACHE II and Charlson Index Score for predicting hospital mortality in critically ill patients. BMC Health Serv Res 2009; 9: 129.

31. Needham DM, Scales DC, Laupacis A, Pronovost PJ. A systematic review of the Charlson comorbidity index using Canadian administrative databases: a perspective on risk adjustment in critical care research. J Crit Care 2005; 20: 12-9.

32. Happe LE, Rao SV, Horblyuk R, Franklin M, Lunacsek OE, Menditto $L$. Consequences of major bleeding in hospitalized patients with non-ST segment elevation acute coronary syndromes receiving injectable anticoagulants. Curr Med Res Opin 2009; 25: 413-20.

33. Greinacher A, Selleng $K$. Thrombocytopenia in the intensive care unit patient. Hematology Am Soc Hematol Educ Program 2010; 2010: 135-43.

34. Katz JN, Kolappa KP, Becker RC. Beyond thrombosis: the versatile platelet in critical illness. Chest 2011; 139: 658-68.

35. Smyth SS, McEver RP, Weyrich AS, et al. Platelet functions beyond hemostasis. J Thromb Haemost 2009; 7: 1759-66.

36. Caruso P, Ferreira AC, Laurienzo CE, et al. Short- and long-term survival of patients with metastatic solid cancer admitted to the intensive care unit: prognostic factors. Eur J Cancer Care (Engl) 2010; 19: 260-6.

37. Vonderheide RH, Thadhani R, Kuter DJ. Association of thrombocytopenia with the use of intra-aortic balloon pumps. Am J Med 1998; 105: 27-32.

38. Kramer AA, Zimmerman JE. Assessing the calibration of mortality benchmarks in critical care: The Hosmer-Lemeshow test revisited. Crit Care Med 2007; 35: 2052-6. 
39. Verma AK, Levine M, Shalansky SJ, Carter CJ, Kelton JG. Frequency of heparin-induced thrombocytopenia in critical care patients. Pharmacotherapy 2003; 23: 745-53.

40. Crowther MA, Cook DJ, Albert M, et al. The 4Ts scoring system for heparin-induced thrombocytopenia in medical-surgical intensive care unit patients. J Crit Care 2010; 25: 287-93.
41. Pace NL. Independent predictors from stepwise logistic regression may be nothing more than publishable P values. Anesth Analg 2008; 107: 1775-8. 